\title{
SIMS for analysis of nanostructures
}

\author{
Edmund G Seebauer ${ }^{\text {a) }}$ \\ Department of Chemical and Biomolecular Engineering, University of Illinois, $600 \mathrm{~S}$ Mathews \\ Ave, Urbana, IL 6182025 \\ D Eitan Barlaz \\ Department of Chemical and Biomolecular Engineering, University of Illinois, $600 \mathrm{~S}$ Mathews \\ Ave, Urbana, IL 6182025
}

a) Electronic mail: eseebaue@illinois.edu

\begin{abstract}
Secondary ion mass spectrometry (SIMS) has joined the ranks of commonplace analytical tools for nanostructures in ways that would have been difficult to foresee even a decade ago. In particular, improvements in numerical data processing have permitted the use of SIMS in one dimension with uneven surfaces and in reconstructing compositional profiles in two and even three dimensions. These developments offer perhaps the brightest prospects for making SIMS a leading member within the select family of first-line characterization tools for nanoelectronics, nanoparticles, and polycrystalline and composite materials - as well as expanding the science base for tailoring such structures.
\end{abstract}

\section{Introduction}

Ever since secondary ion mass spectrometry (SIMS) originated in the 1970s as a surface analytical tool [1], the fundamental principle of operation has remained the same: ions impinge on a solid that sputter some of the atoms, whose masses are determined by mass spectrometry. The resulting mass spectrum yields a measurement of the composition that is exquisitely sensitive. This concept has spawned a variety of ion sources (electron ionization for gases, surface ionization for $\mathrm{Cs}$, liquid metal). Choice depends upon the required current, usage in pulsed or continuous mode, spot size, and specimen properties. $\mathrm{Cs}^{+}$ions often compose the primary incident beam, and provide both sputtering and milling. Yet $\mathrm{Cs}^{+}$tends to form complex ions, especially with oxygen; thus many other atomic ions find use including $\mathrm{Ar}^{+}, \mathrm{O}^{-}, \mathrm{O}^{+}, \mathrm{Ga}^{+}$, and $\mathrm{Xe}^{+}$. For the large secondary ion masses characteristic of polymeric and biological specimens, cluster ion beams, such as $\mathrm{C}_{60}{ }^{+}$, are employed. Mass identification employs sector, quadrupole, or time-of-flight (TOF) analyzers. Most SIMS instruments can run in either static or dynamic modes. In static mode, the energy and fluence of the primary ion beam are sufficiently low to remove very few of surface atoms, providing minimal invasiveness. Pulsed primary ions with TOF detection permits simultaneous detection of many masses but is slow. Dynamic mode employs higher ion energies and fluxes for continuous compositional profiling over substantial depths. Hybrid methods combine the two modes in alternation, typically with two separate primary ion beams.

Building upon earlier examples [2], several fine book-length reviews of these variants have appeared in recent years providing either a general overview [1] or insights into specific modes of operation [3] or applications [4-5]. Shorter, more focused reviews have also appeared treating materials science [6], organic molecules [7], and soft materials that include polymers [5, 

nanostructured surfaces does not appear to have been examined specifically.

SIMS offers no silver bullet for characterization, but rather exists as one useful tool among many. SIMS is most naturally a one dimensional technique, capable of superlative depth resolution (1-2 nm), but more limited lateral resolution no larger than the spot size $(50-100 \mathrm{~nm})$ for imaging individual structures in 2-D [11] or 3-D [12]. Moreover, SIMS is most naturally an atomic composition technique, although use for molecular composition is developing in applications focused mainly upon biology [13], polymers [14] and organic chemistry [15].

Despite the limitations, a key development over the past few years has been the integration of SIMS into the family of techniques that provide first-line nanostructural characterization. From basic research to metrology in a manufacturing line, SIMS has joined the ranks of commonplace analytical tools in ways that would have been difficult to foresee even a decade ago.

\section{Methodological Advances}

\section{Spatial resolution}

Depth

Improvements in depth resolution continue to progress, and now lie somewhat below 1 $\mathrm{nm}$ with the use of low incident ion energies < $150 \mathrm{eV}$ [16-17] and extremely smooth surfaces Under such conditions, however, the sputtering rate drops sufficiently low to impede detection, thereby degrading either mass separation or profiling rates $(<1 \mathrm{~nm} / \mathrm{min})$. Certain physical phenomena limit localized depth resolution both near the free surface and in more deeply buried structures. For example, intermixing from the beam-induced collision cascade represents a fundamental constraint [16]. Most progress has resulted from using lower beam energies [18], but as that approach runs out of steam, attention has turned to use of beams of alternate ions or even cluster-ion beams (e.g., $\left.\mathrm{C}_{60}{ }^{+}[19]\right)$. Clusters offer reduced penetration depths but introduce other nonlinear effects due to the many-body nature of the sputtering process. Primary ion incorporation and other compound formation are particularly troublesome in the vicinity of the free surface, as the concentration of the impinging ion builds up transiently and affects sputtering yields and intermixing effects in a depth-dependent way.

Absolute depths are typically calibrated by exposure of a reference specimen to the primary beam, followed by ex situ measurement of crater depth by atomic force microscopy (AFM) or stylus profilometry [19-21]. If these techniques are applied directly to the specimen of interest, they are applied after the SIMS measurement [5, 22], leading to possible artifacts from embedded Cs, surface reconstruction or specimen oxidation upon removal from UHV conditions $[23]$.

Given these fundamental complications, it is difficult to foresee much further improvement in depth resolution by conventional SIMS. Depth resolutions approaching $0.5 \mathrm{~nm}$ may become possible via entirely distinct concepts, such as Tomographic Atomprobe or "zeroenergy SIMS." In the former case, material emission depends upon laser-assisted electric field evaporation, while the latter relies upon electron-beam induced etching in the presence of a reactive gas such as $\mathrm{XeF}_{2}$ [24]. However, these methods are restricted to particularly favorable matrices and analytes, and forego the generality of SIMS to many materials.

Lateral \& 3D 
Improvements in primary beam focusing and secondary ion detection has pushed lateral resolution as low as $50 \mathrm{~nm}$ [25-26], permitting direct imaging of elemental segregation at grain boundaries in certain polycrystalline solids [11,27]. Figure 1 shows an example. Further resolution may be obtained by matching the primary beam with one of the analytes and detecting secondary cluster ions of this species. Such "self-focusing" SIMS promises lateral resolution as low as $20 \mathrm{~nm}$ but is still in its infancy [28].

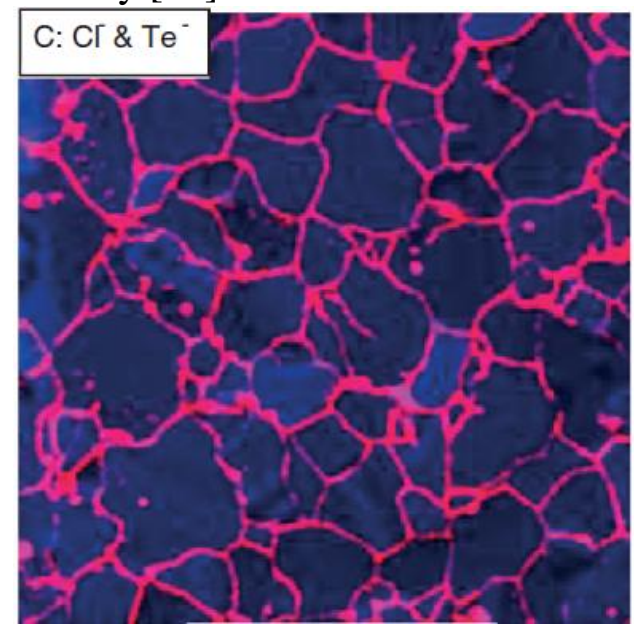

Figure 1: (Color Online) Polycrystalline CdTe after $\mathrm{CdCl}_{2}$ treatment. $\mathrm{Cl}^{-}$(pink) and $\mathrm{Te}^{-}$(blue) demonstrate atomic chloride segregation at grain boundaries. Image size: $26 * 26 \mu \mathrm{m}$ using a $256 * 256$ pixel scan. Reprinted with permission from Ref [11], Figure 2C. Copyright 2014 John Wiley and Sons.

Data analysis by numerical methods has advanced considerably in recent years to aid in 2D and 3D compositional analysis. Such methods rely upon separate data, often collected in situ, regarding sputtering rate [29] and surface topography [12,30]. Figure 2 shows an example approach that integrates SIMS with scanning probe microscopy (SPM).

(a)

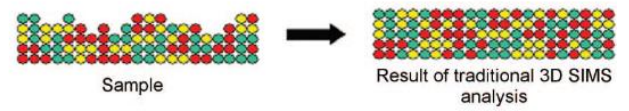

(b)

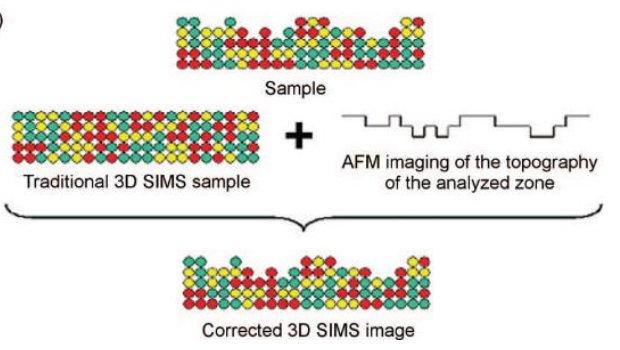

Figure 2: $3 D$ SIMS in the presence of three elements and surface roughness. (a) Standard SIMS 3D mapping: poor accuracy due to inappropriate assumption of flatness. (b) Successive SIMS and SPM/AFM images, and software reconstruction, account for sample topography and its evolution during sputtering. Reprinted with permission from Ref [12], Figure 1. Copyright 2012 AIP Publishing LLC. 


\section{Concentration}

Despite the exquisite sensitivity of SIMS on a relative scale into the parts per billion range, absolute concentration measurements remain a multifaceted problem dependent on beam type and sample composition. The ionization likelihood for an analyte varies with beam type and energy. Formation of ion complexes between the analyte and matrix can induce deviations of ion yields by orders of magnitude from the "neat" analyte [31]. When the analyte is not dilute, sputtering yields depend upon concentration relative to the matrix. Incorporation of the primary ion into the intermixed layer affects composition resolution further, especially if a new compound (such as an oxide) forms. Absolute concentration measurements therefore require standard samples of known concentrations, with numerical principal component analysis [20, 3233] finding use for complex compositions. Other externally supplied information such as natural isotopic abundances may also be employed [26]. Such requirements have remained constant throughout the years and are unlikely to change in the future.

\section{Applications}

Most of the recent extensions of SIMS into new domains of application have resulted from improvements in lateral and depth resolution afforded by advances in commercial instrumentation. Individual research laboratories typically contribute to improved protocols for specimen preparation, numerical data analysis and interpretation, and integration of SIMS with other tools [34] for investigation of ever-smaller structures.

SIMS is an intrinsically destructive technique. Its applications therefore remain mostly in the domain of research and development rather than manufacturing. The laboratory setting focuses on maximal spatial resolution and accuracy in absolute concentration measurements, whereas the fabrication environment seeks mainly low-cost methods that provide rapid, statistically relevant data for yield improvement and process control. Despite its complexity, SIMS is being increasingly viewed as a "lab to fab" technique for electronic devices, especially with the possibility of self-focusing. Commercial instruments for manufacturing have become available for near-line metrology [35].

Irrespective of application, SIMS has cemented its place as a favorable compositional characterization tool due to the robust nature of operation and straightforward analysis. The closest competition to SIMS in 2-D or 3-D combines a surface technique, such as X-ray photoelectron spectroscopy (XPS) or Auger electron spectroscopy (AES), with ion milling for depth profiling [36]. XPS can achieve comparable lateral resolution and has the dual advantages of sensitivity to chemical valence state and use of X-rays as a less intrusive probe than ions. This gentler perturbation avoid the collision cascades that degrade near surface depth resolution for SIMS as discussed above. However, XPS has difficulty detecting lighter elements (especially hydrogen), and the requirement of ion milling for depth profiling reintroduces the same collisional mixing and preferential milling problems that SIMS suffers.

\section{$\underline{\text { Nanoelectronics }}$}

The two greatest contributions to SIMS for micro- and nanoelectronics have probably been a) the integration of SIMS as part of the family of go-tool characterization tools, and b) the improvement in software packages for reconstructing SIMS data into profiles in 2D and 3D. Much work incorporated SIMS into multifaceted examinations with complimentary techniques 
including scanning probe microscopies [12, 29, 37], Hall effect measurements [21] and resistance-based microscopies [38], and high-resolution X-ray diffraction (XRD) [29, 37]. Most complimentary techniques are compatible with the high vacuum required by SIMS, making in situ monitoring possible.

The sub-nm depth resolution of SIMS in some cases is quite adequate for many purposes, although the surface unevenness of actual devices poses difficult problems. Lateral resolution of $50 \mathrm{~nm}$ is typically too large for imaging individual nanoelectronic devices, and this limitation is unlikely to be surmounted soon. Applications requiring such resolution often turn to highly specialized atomic probe techniques [39], sometimes as a complement to SIMS.

\section{Nanoparticles}

Direct characterization of nanoparticles by SIMS is becoming more common, including not only particles of a single nominal composition [40] but also core-shell structures [19] and organic-coated particles [35]. However, possible artifacts are significant. Sputtering of nanoparticles often occurs at rates different from those of thin films or bulk materials, so depth information may be unreliable. Needs for complimentary composition information often turn to in situ XPS [40-42].

Even when very low primary ion energies are employed, melting may occur within the particle due to inadequate heat transfer to its substrate [19]. Such melting further complicates the interpretation of depth profiles. Complimentary topological information is often obtained using SEM [41] and TEM [25, 41] for a more complete image of the sample.

\section{Grain structure and spatial composition in polycrystalline and composite materials}

Two-dimensional SIMS measurements have found an important niche in analysis of polycrystalline materials, including compositional and isotopic analysis of minerals for geochemistry and cosmochemistry [18], corrosion monitoring of alloys for nuclear reactors [4344], and other applications [19]. Elemental segregation to grain boundaries can be quantified even when the width of the grain boundary itself is substantially less than the ion beam's spot size $[11,45]$. Application to a metal permits polishing that facilitates accuracy. The procedure assumes that sputter yields and ionization probabilities are identical from a scanned area lying entirely within in a bulk grain and an area containing a grain boundary. The total volume of material contributing to the analysis is much larger than the volume of grain boundary. Hence, the matrix including and excluding the boundary is largely identical. Similar to nanoparticles, complimentary techniques for both morphology and composition data are common often including (XPS) [23, 42], atomic force microscopy [22-23], Auger electron spectroscopy [23], energy-dispersive X-ray spectroscopy [43, 46], scanning electron microscopy (SEM) [43-44] and transmission electron microscopy (TEM) [44, 46].

In a related vein, direct mapping of elemental segregation in glasses has also been demonstrated [46], again facilitated by the smooth surfaces. Soil and sediment particles can be examined by embedding them in a polymeric resin, and polishing the composite [42]. This procedure eliminates topographical variations in local sputtering efficiencies by losing a majority of the outer surface of the particle.

\section{$\underline{\text { Science base for nanotechnology }}$}

SIMS has played a linchpin role in discovering new phenomena that have direct relevance for fabrication of nanostructures. One example is atomic-scale defect engineering, 
which involves manipulating the type, concentration, spatial distribution, or mobility of defects within a crystalline solid [47]. Such defects mediate dopant diffusion in semiconductors used for nanoelectronic devices and affect the performance of semiconductor-based sensors, catalysts, photo-active devices, and photovoltaic cells. Example methods for achieving such control include specially designed heating protocols (time, maximum temperature, heating and cooling rates) and introduction of foreign atoms. A more recent approach includes controlling the chemical state of nearby free surfaces, which is important at the nanoscale where surface-tovolume ratios are high. The surface injects or annihilates point defects in $\mathrm{Si}$ [48], $\mathrm{TiO}_{2}$ [49-50], and $\mathrm{ZnO}$ [P Gorai et al., submitted] by preferential interaction with dangling bonds or related sites, in ways that are mediated by surface electric fields [51-53]. The effects of this method can be seen in Figure 3. Recently, the ability to absorb oxygen via a mobile defect has enabled a better understanding of the performance of $\mathrm{TiO}_{2}$ as an oxygen scavenging material [54]. Another such method is photostimulation, which can exert nonthermal effects by changing the charge state of point defects within the semiconductor [55-57] or at a surface or interface [58]. This phenomenon is relevant to nanoscale device fabrication by rapid thermal processing. These experiments relied heavily on self-diffusion measurements made by depth profiling of isotopic heterostructures or isotopic exchange with an ambient gas. SIMS depth profiling, combined with continuum modeling of defect-mediated diffusion [59-60], were indispensable in uncovering the underlying defect physics. Depth scales below $10 \mathrm{~nm}$ were often entailed [53].

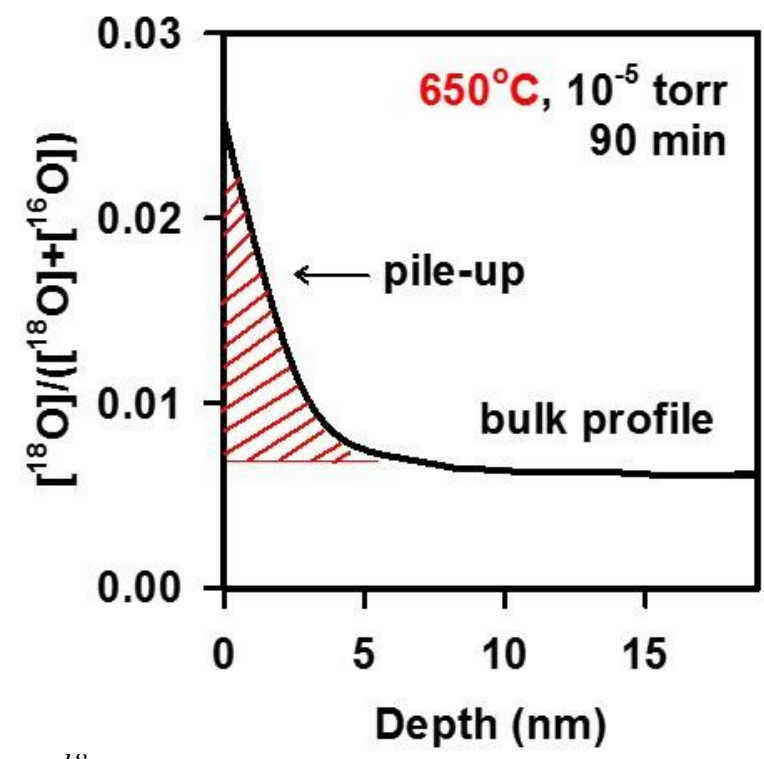

Figure 3: Depth profile of ${ }^{18} \mathrm{O}$ near a rutile $\mathrm{TiO}_{2}(110)$ surface. The single crystal is annealed in ${ }^{18} \mathrm{O}_{2}$ gas to stimulate oxygen exchange between the gas and solid. For very clean surfaces, $O$ is injected in interstitial form charged (-2). The built-in electric field due to surface band bending opposes diffusive motion of the interstitials, which gives them more time to kick into the lattice and pile up over time. See Refs [50-52] for details.

\section{Conclusion}


Fundamental physical limits have been largely reached for depth resolution, but improvements in both spot sizes and numerical data processing continue to offer prospects for advancing use of SIMS in 1-D with uneven surfaces and in reconstructing compositional profiles in 2D and 3D. These developments, together with refinement of protocols for minimizing sputtering yield variations from local topography offer perhaps the brightest prospects for confirming SIMS as a leading member within the family of first-line characterization tools.

\section{Acknowledgements}

Authors gratefully acknowledge support from the National Science Foundation (DMR 10-05720 and DMR 13-06822).

\section{References \& Recommended Reading}

1. Van der Heide, P., Secondary ion mass spectrometry : an introduction to principles and practices. John Wiley \& Sons, Inc.: Hoboken, New Jersey, 2014.

2. Wilson, R. G.; Magee, C. W.; Stevie, F. A., Secondary ion mass spectrometry: a practical handbook for depth profiling and bulk impurity analysis. Wiley: New York, 1989; p 1 v. (various pagings).

3. Mahoney, C. M., Cluster Secondary Ion Mass Spectrometry: Principles and Applications. Wiley: Hoboken, New Jersey, 2013.

4. Grice, K., Principles and Practice of Analytical Techniques in Geosciences. The Royal Society of Chemistry: Cambridge, UK, 2015.

5. Mahoney, C. M., Cluster secondary ion mass spectrometry of polymers and related materials. Mass Spectrometry Reviews 2010, 29 (2), 247-293.

6. McPhail, D. S., Applications of Secondary Ion Mass Spectrometry (SIMS) in Materials Science. J Mater Sci 2006, 41 (3), 873-903.

7. Fletcher, J. S.; Vickerman, J. C., Secondary Ion Mass Spectrometry: Characterizing Complex Samples in Two and Three Dimensions. Analytical Chemistry 2013, 85 (2), 610-639. 8. Chi-Ming, C.; Lu-Tao, W.; Lau, Y.-T. R., Polymer surface structures determined using ToF-SIMS. Reviews in Analytical Chemistry 2014, 33 (1), 11-30.

9. Boxer, S. G.; Kraft, M. L.; Weber, P. K., Advances in Imaging Secondary Ion Mass Spectrometry for Biological Samples. Annual Review of Biophysics 2009, 38 (1), 53-74. 10. Thiel, V.; Sjövall, P., Using Time-of-Flight Secondary Ion Mass Spectrometry to Study Biomarkers. Annual Review of Earth and Planetary Sciences 2011, 39 (1), 125-156.

11. Harvey, S. P.; Teeter, G.; Moutinho, H.; Al-Jassim, M. M., Direct evidence of enhanced chlorine segregation at grain boundaries in polycrystalline CdTe thin films via three-dimensional TOF-SIMS imaging. Progress in Photovoltaics: Research and Applications 2015, 23 (7), 838846.

12. Wirtz, T.; Fleming, Y.; Gerard, M.; Gysin, U.; Glatzel, T.; Meyer, E.; Wegmann, U.; Maier, U.; Odriozola, A. H.; Uehli, D., Design and performance of a combined secondary ion mass spectrometry-scanning probe microscopy instrument for high sensitivity and highresolution elemental three-dimensional analysis. Review of Scientific Instruments 2012, 83 (6), 063702.

13. Fornai, L.; Angelini, A.; Klinkert, I.; Giskes, F.; Kiss, A.; Eijkel, G.; Amstalden-van Hove, E. A.; Klerk, L. A.; Fedrigo, M.; Pieraccini, G.; Moneti, G.; Valente, M.; Thiene, G.; 
Heeren, R. M., Three-dimensional molecular reconstruction of rat heart with mass spectrometry imaging. Anal Bioanal Chem 2012, 404 (10), 2927-2938.

14. Marchany, M. D.; Gardella, J. A.; Kuchera, T. J., Time of flight secondary ion mass spectrometry surface and in-depth study of degradation of nanosheet poly(l-lactic acid) films. Biointerphases 2015, 10 (1), 019010.

15. Szynkowska, M. I.; Czerski, K.; Rogowski, J.; Paryjczak, T.; Parczewski, A., ToF-SIMS application in the visualization and analysis of fingerprints after contact with amphetamine drugs. Forensic Science International 2009, 184 (1-3), e24-e26.

16. Vandervorst, W., Semiconductor profiling with sub-nm resolution: Challenges and solutions. Applied Surface Science 2008, 255 (4), 805-812.

17. Merkulov, A.; Peres, P.; Choi, S.; Horreard, F.; Ehrke, H.-U.; Loibl, N.; Schuhmacher, M., Advanced secondary ion mass spectroscopy quantification in the first few nanometer of B, P, and As ultrashallow implants. Journal of Vacuum Science \&amp; Technology B 2010, 28 (1), C1C48-C1C53.

18. Dowsett, M. G., Depth profiling using ultra-low-energy secondary ion mass spectrometry. Applied Surface Science 2003, 203-204, 5-12.

19. Yang, L.; Seah, M. P.; Gilmore, I. S.; Morris, R. J. H.; Dowsett, M. G.; Boarino, L.; Sparnacci, K.; Laus, M., Depth Profiling and Melting of Nanoparticles in Secondary Ion Mass Spectrometry (SIMS). The Journal of Physical Chemistry C 2013, 117 (31), 16042-16052. 20. Hofmeister, C.; Klimov, M.; Deleghanty, T.; Cho, K.; Sohn, Y., Quantification of nitrogen impurity and estimated Orowan strengthening through secondary ion mass spectroscopy in aluminum cryomilled for extended durations. Materials Science and Engineering: A 2015, 648, 412-417.

21. Yuen-Yee, W.; Edward Yi, C.; Wei-Ching, H.; Yueh-Chin, L.; Yung-Yi, T.; Kai-Wei, C.; Hung-Wei, Y., Effects of initial GaN growth mode on the material and electrical properties of AlGaN/GaN high-electron-mobility transistors. Applied Physics Express 2014, 7 (9), 095502. 22. Wucher, A.; Cheng, J.; Zheng, L.; Willingham, D.; Winograd, N., Three-dimensional molecular imaging using mass spectrometry and atomic force microscopy. Applied Surface Science 2008, 255 (4), 984-986.

23. Ngo, K. Q.; Philipp, P.; Kieffer, J.; Wirtz, T., Cs oxide aggregation in SIMS craters in organic samples for optoelectronic application. Surface Science 2012, 606 (15-16), 1244-1251. 24. Vanhove, N.; Lievens, P.; Vandervorst, W., Zero-energy SIMS depth profiling: the role of surface roughness development with $\mathrm{XeF}_{2}$-based etching. Surface and Interface Analysis 2011, 43 (1-2), 159-162.

25. Moreau, J. W.; Weber, P. K.; Martin, M. C.; Gilbert, B.; Hutcheon, I. D.; Banfield, J. F., Extracellular Proteins Limit the Dispersal of Biogenic Nanoparticles. Science 2007, 316 (5831), 1600-1603.

26. Hoppe, P.; Cohen, S.; Meibom, A., NanoSIMS: Technical Aspects and Applications in Cosmochemistry and Biological Geochemistry. Geostandards and Geoanalytical Research 2013, 37 (2), 111-154.

27. Valle, N.; Drillet, J.; Pic, A.; Migeon, H. N., Nano-SIMS investigation of boron distribution in steels. Surface and Interface Analysis 2011, 43 (1-2), 573-575.

28. Franquet, A.; Douhard, B.; Melkonyan, D.; Delmotte, J.; Demeulemeester, J.; Conard, T.; Vandervorst, W. In Quantification of Group IV Alloys in Confined Structures: the Self Focusing SIMS Approach, SIMS Europe, Münster, Germany, Arlinghaus, H. F., Ed. Münster, Germany, 2014. 
29. Shin, H.-C.; Song, J.-T., High resolution 3-D imaging for characteristics of (111)oriented $\mathrm{Pb}\left(\mathrm{Zr}_{0.35} \mathrm{Ti}_{0.65}\right) \mathrm{O}_{3}$ thin film by using time-of-flight secondary ion mass spectrometry and piezoresponse force microscopy. Electron. Mater. Lett. 2011, 7 (3), 265-270.

30. Swart, H. C.; Nagpure, I. M.; Ntwaeaborwa, O. M.; Fisher, G. L.; Terblans, J. J., Identification of Eu oxidation states in a doped $\mathrm{Sr}_{5}\left(\mathrm{PO}_{4}\right)_{3} \mathrm{~F}$ phosphor by TOF-SIMS imaging. Opt. Express 2012, 20 (15), 17119-17125.

31. Shimizu, N.; Hart, S. R., Isotope fractionation in secondary ion mass spectrometry. Journal of Applied Physics 1982, 53 (3), 1303-1311.

32. Sahu, D. K.; Agrawal, S.; Saji, J., Study the Hardness Properties of TiAlN Coatings Prepared by Magnetron Co-sputtering Deposited Nanoscale Multi-layered Structure. AIP Conference Proceedings 2011, 1372 (1), 318-322.

33. Drozdov, M. N.; Vostokov, N. V.; Danil'tsev, V. M.; Demidov, E. V.; Drozdov, Y. N.; Khrykin, O. I.; Shashkin, V. I., Quantitative analysis of the elemental composition and electron concentration in $\mathrm{AlGaN} / \mathrm{GaN}$ heterostructures with a two-dimensional electron channel by means of SIMS and C-V profiling. Bull. Russ. Acad. Sci. Phys. 2012, 76 (2), 221-224.

34. Chou, H.; Ismach, A.; Ghosh, R.; Ruoff, R. S.; Dolocan, A., Revealing the planar chemistry of two-dimensional heterostructures at the atomic level. Nature Communications 2015, 6 .

35. Schnieders, A.; Budri, T. In Full wafer defect analysis with time-of-flight secondary Ion Mass Spectrometry, Advanced Semiconductor Manufacturing Conference (ASMC), 2010 IEEE/SEMI, 11-13 July 2010; 2010; pp 158-161.

36. Ziemniak, S. E.; Hanson, M., Corrosion behavior of NiCrFe Alloy 600 in high temperature, hydrogenated water. Corrosion Science 2006, 48 (2), 498-521.

37. Sang Ho, L.; Dong Ju, O.; Ah Young, H.; Dong Suk, H.; Shin, K.; Jae Kyeong, J.; Jong Wan, P., Improvement in Device Performance of a-InGaZnO Transistors by Introduction of CaDoped $\mathrm{Cu}$ Source/Drain Electrode. Electron Device Letters, IEEE 2015, 36 (8), 802-804.

38. Dhar, R. S.; Ban, D., Two-dimensional profiling of carriers in terahertz quantum cascade lasers using calibrated scanning spreading resistance microscopy and scanning capacitance microscopy. Journal of Microscopy 2013, 251 (1), 35-44.

39. Perea, D. E.; Allen, J. E.; May, S. J.; Wessels, B. W.; Seidman, D. N.; Lauhon, L. J., Three-Dimensional Nanoscale Composition Mapping of Semiconductor Nanowires. Nano Letters 2006, 6 (2), 181-185.

40. Stepien, M.; Saarinen, J. J.; Teisala, H.; Tuominen, M.; Aromaa, M.; Haapanen, J.; Kuusipalo, J.; Mäkelä, J. M.; Toivakka, M., ToF-SIMS Analysis of UV-Switchable $\mathrm{TiO}_{2}$ Nanoparticle-Coated Paper Surface. Langmuir 2013, 29 (11), 3780-3790.

41. Carraro, G.; Gasparotto, A.; Maccato, C.; Bontempi, E.; Lebedev, O. I.; Turner, S.; Sada, C.; Depero, L. E.; Van Tendeloo, G.; Barreca, D., Fluorine doped $\mathrm{Fe}_{2} \mathrm{O}_{3}$ nanostructures by a onepot plasma-assisted strategy. RSC Advances 2013, 3 (45), 23762-23768.

42. Höschen, C.; Höschen, T.; Mueller, C. W.; Lugmeier, J.; Elgeti, S.; Rennert, T.; KögelKnabner, I., Novel Sample Preparation Technique To Improve Spectromicroscopic Analyses of Micrometer-Sized Particles. Environmental Science \& Technology 2015, 49 (16), 9874-9880. 43. Gázquez, M. C.; Hernández, T.; Muktepavela, F.; Platacis, E.; Shishko, A., Magnetic field effect on the corrosion processes at the Eurofer- $\mathrm{Pb}-17 \mathrm{Li}$ flow interface. Journal of Nuclear Materials 2015, 465, 633-639.

44. Schreiber, D. K.; Olszta, M. J.; Saxey, D. W.; Kruska, K.; Moore, K. L.; Lozano-Perez, S.; Bruemmer, S. M., Examinations of Oxidation and Sulfidation of Grain Boundaries in Alloy 
600 Exposed to Simulated Pressurized Water Reactor Primary Water. Microscopy and Microanalysis 2013, 19 (03), 676-687.

45. Christien, F.; Downing, C.; Moore, K. L.; Grovenor, C. R. M., Quantitative grain boundary analysis of bulk samples by SIMS. Surface and Interface Analysis 2013, 45 (1), 305308.

46. Gin, S.; Guittonneau, C.; Godon, N.; Neff, D.; Rebiscoul, D.; Cabié, M.; Mostefaoui, S., Nuclear Glass Durability: New Insight into Alteration Layer Properties. The Journal of Physical Chemistry C 2011, 115 (38), 18696-18706.

47. Seebauer, E. G.; Noh, K. W., Trends in semiconductor defect engineering at the nanoscale. Materials Science and Engineering: R: Reports 2010, 70 (3-6), 151-168.

48. $\quad$ Seebauer, E. G.; Dev, K.; Jung, M. Y. L.; Vaidyanathan, R.; Kwok, C. T. M.; Ager, J. W.; Haller, E. E.; Braatz, R. D., Control of Defect Concentrations within a Semiconductor through Adsorption. Physical Review Letters 2006, 97 (5), 055503.

49. Hollister, A. G.; Gorai, P.; Seebauer, E. G., Surface-based manipulation of point defects in rutile $\mathrm{TiO}_{2}$. Applied Physics Letters 2013, 102 (23), 231601.

50. Gorai, P.; Hollister, A. G.; Pangan-Okimoto, K.; Seebauer, E. G., Kinetics of oxygen interstitial injection and lattice exchange in rutile $\mathrm{TiO}_{2}$. Applied Physics Letters 2014, 104 (19), 191602.

51. Gorai, P.; Kondratenko, Y. V.; Seebauer, E. G., Mechanism and kinetics of near-surface dopant pile-up during post-implant annealing. Journal of Applied Physics 2012, 111 (9), 094510. 52. Gorai, P.; Seebauer, E. G., Kinetic model for electric-field induced point defect redistribution near semiconductor surfaces. Applied Physics Letters 2014, 105 (2), 021604. 53. Gorai, P.; Hollister, A. G.; Seebauer, E. G., Electrostatic drift effects on near-surface defect distribution in $\mathrm{TiO}_{2}$. Applied Physics Letters 2013, 103 (14), 141601.

54. Close, T.; Tulsyan, G.; Diaz, C. A.; Weinstein, S. J.; Richter, C., Reversible oxygen scavenging at room temperature using electrochemically reduced titanium oxide nanotubes. Nat Nano 2015, 10 (5), 418-422.

55. Seebauer, E. G.; Jung, M. Y. L.; Kwok, C. T. M.; Vaidyanathan, R.; Kondratenko, Y. V., Measurement of photostimulated self-diffusion in silicon. Journal of Applied Physics 2011, 109 (10), 103708.

56. Vaidyanathan, R.; Felch, S.; Graoui, H.; Foad, M. A.; Kondratenko, Y.; Seebauer, E. G., Nonthermal illumination effects on ultra-shallow junction formation. Applied Physics Letters 2011, 98 (19), 194104.

57. Stathopoulos, S.; Tsetseris, L.; Pradhan, N.; Colombeau, B.; Tsoukalas, D., Millisecond non-melt laser annealing of phosphorus implanted germanium: Influence of nitrogen co-doping. Journal of Applied Physics 2015, 118 (13), 135710.

58. Kondratenko, Y.; Seebauer, E. G., Interface-Mediated Photostimulation Effects on Diffusion and Activation of Boron Implanted into Silicon. ECS Journal of Solid State Science and Technology 2013, 2 (5), P235-P242.

59. Gorai, P.; Hollister, A. G.; Seebauer, E. G., Measurement of Defect-Mediated Oxygen Self-Diffusion in Metal Oxides. ECS Journal of Solid State Science and Technology 2012, 1 (2), Q21-Q24.

60. Pangan-Okimoto, K. M.; Gorai, P.; Hollister, A. G.; Seebauer, E. G., Model for Oxygen Interstitial Injection from the Rutile $\mathrm{TiO}_{2}(110)$ Surface into the Bulk. The Journal of Physical Chemistry C 2015, 119 (18), 9955-9965. 
1. Van der Heide, P., Secondary ion mass spectrometry : an introduction to principles and practices. John Wiley \& Sons, Inc.: Hoboken, New Jersey, 2014.

- Book length review including extensive descriptions of ion chemistries, instrument hardware, and signal processing software.

2. Wilson, R. G.; Magee, C. W.; Stevie, F. A., Secondary ion mass spectrometry: a practical handbook for depth profiling and bulk impurity analysis. Wiley: New York, 1989; p 1 v. (various pagings).

3. Mahoney, C. M., Cluster Secondary Ion Mass Spectrometry: Principles and Applications. Wiley: Hoboken, New Jersey, 2013.

- Book length review highlights the capabilities of cluster-ion SIMS with detailed information about non-linear effect and matching cluster ion selection with sample composition.

4. Grice, K., Principles and Practice of Analytical Techniques in Geosciences. The Royal Society of Chemistry: Cambridge, UK, 2015.

5. Mahoney, C. M., Cluster secondary ion mass spectrometry of polymers and related materials. Mass Spectrometry Reviews 2010, 29 (2), 247-293.

6. McPhail, D. S., Applications of Secondary Ion Mass Spectrometry (SIMS) in Materials Science. J Mater Sci 2006, 41 (3), 873-903.

7. $\quad$ Fletcher, J. S.; Vickerman, J. C., Secondary Ion Mass Spectrometry: Characterizing Complex Samples in Two and Three Dimensions. Analytical Chemistry 2013, 85 (2), 610-639. 8. Chi-Ming, C.; Lu-Tao, W.; Lau, Y.-T. R., Polymer surface structures determined using ToF-SIMS. Reviews in Analytical Chemistry 2014, 33 (1), 11-30.

9. Boxer, S. G.; Kraft, M. L.; Weber, P. K., Advances in Imaging Secondary Ion Mass Spectrometry for Biological Samples. Annual Review of Biophysics 2009, 38 (1), 53-74.

10. Thiel, V.; Sjövall, P., Using Time-of-Flight Secondary Ion Mass Spectrometry to Study Biomarkers. Annual Review of Earth and Planetary Sciences 2011, 39 (1), 125-156.

11. Harvey, S. P.; Teeter, G.; Moutinho, H.; Al-Jassim, M. M., Direct evidence of enhanced chlorine segregation at grain boundaries in polycrystalline CdTe thin films via three-dimensional TOF-SIMS imaging. Progress in Photovoltaics: Research and Applications 2015, 23 (7), 838846.

- Demonstration of high lateral resolution 2D SIMS and discussion of implications for measurements in polycrystalline materials.

12. Wirtz, T.; Fleming, Y.; Gerard, M.; Gysin, U.; Glatzel, T.; Meyer, E.; Wegmann, U.; Maier, U.; Odriozola, A. H.; Uehli, D., Design and performance of a combined secondary ion mass spectrometry-scanning probe microscopy instrument for high sensitivity and highresolution elemental three-dimensional analysis. Review of Scientific Instruments 2012, 83 (6), 063702.

13. Fornai, L.; Angelini, A.; Klinkert, I.; Giskes, F.; Kiss, A.; Eijkel, G.; Amstalden-van Hove, E. A.; Klerk, L. A.; Fedrigo, M.; Pieraccini, G.; Moneti, G.; Valente, M.; Thiene, G.; Heeren, R. M., Three-dimensional molecular reconstruction of rat heart with mass spectrometry imaging. Anal Bioanal Chem 2012, 404 (10), 2927-2938. 
14. Marchany, M. D.; Gardella, J. A.; Kuchera, T. J., Time of flight secondary ion mass spectrometry surface and in-depth study of degradation of nanosheet poly(l-lactic acid) films. Biointerphases 2015, 10 (1), 019010.

15. Szynkowska, M. I.; Czerski, K.; Rogowski, J.; Paryjczak, T.; Parczewski, A., ToF-SIMS application in the visualization and analysis of fingerprints after contact with amphetamine drugs. Forensic Science International 2009, 184 (1-3), e24-e26.

16. Vandervorst, W., Semiconductor profiling with sub-nm resolution: Challenges and solutions. Applied Surface Science 2008, 255 (4), 805-812.

17. Merkulov, A.; Peres, P.; Choi, S.; Horreard, F.; Ehrke, H.-U.; Loibl, N.; Schuhmacher, M., Advanced secondary ion mass spectroscopy quantification in the first few nanometer of B, P, and As ultrashallow implants. Journal of Vacuum Science \&amp; Technology B 2010, 28 (1), C1C48-C1C53.

18. Dowsett, M. G., Depth profiling using ultra-low-energy secondary ion mass spectrometry. Applied Surface Science 2003, 203-204, 5-12.

19. Yang, L.; Seah, M. P.; Gilmore, I. S.; Morris, R. J. H.; Dowsett, M. G.; Boarino, L.; Sparnacci, K.; Laus, M., Depth Profiling and Melting of Nanoparticles in Secondary Ion Mass Spectrometry (SIMS). The Journal of Physical Chemistry C 2013, 117 (31), 16042-16052. $\bullet \bullet$ Challenges and successes of imaging nanoparticles using SIMS.

20. Hofmeister, C.; Klimov, M.; Deleghanty, T.; Cho, K.; Sohn, Y., Quantification of nitrogen impurity and estimated Orowan strengthening through secondary ion mass spectroscopy in aluminum cryomilled for extended durations. Materials Science and Engineering: A 2015, 648, 412-417.

21. Yuen-Yee, W.; Edward Yi, C.; Wei-Ching, H.; Yueh-Chin, L.; Yung-Yi, T.; Kai-Wei, C.; Hung-Wei, Y., Effects of initial GaN growth mode on the material and electrical properties of AlGaN/GaN high-electron-mobility transistors. Applied Physics Express 2014, 7 (9), 095502. 22. Wucher, A.; Cheng, J.; Zheng, L.; Willingham, D.; Winograd, N., Three-dimensional molecular imaging using mass spectrometry and atomic force microscopy. Applied Surface Science 2008, 255 (4), 984-986.

23. Ngo, K. Q.; Philipp, P.; Kieffer, J.; Wirtz, T., Cs oxide aggregation in SIMS craters in organic samples for optoelectronic application. Surface Science 2012, 606 (15-16), 1244-1251. 24. Vanhove, N.; Lievens, P.; Vandervorst, W., Zero-energy SIMS depth profiling: the role of surface roughness development with XeF2-based etching. Surface and Interface Analysis 2011, 43 (1-2), 159-162.

25. Moreau, J. W.; Weber, P. K.; Martin, M. C.; Gilbert, B.; Hutcheon, I. D.; Banfield, J. F., Extracellular Proteins Limit the Dispersal of Biogenic Nanoparticles. Science 2007, 316 (5831), 1600-1603.

26. Hoppe, P.; Cohen, S.; Meibom, A., NanoSIMS: Technical Aspects and Applications in Cosmochemistry and Biological Geochemistry. Geostandards and Geoanalytical Research 2013, 37 (2), 111-154.

27. Valle, N.; Drillet, J.; Pic, A.; Migeon, H. N., Nano-SIMS investigation of boron distribution in steels. Surface and Interface Analysis 2011, 43 (1-2), 573-575.

28. Franquet, A.; Douhard, B.; Melkonyan, D.; Delmotte, J.; Demeulemeester, J.; Conard, T.; Vandervorst, W. In Quantification of Group IV Alloys in Confined Structures: the Self Focusing SIMS Approach, SIMS Europe, Münster, Germany, Arlinghaus, H. F., Ed. Münster, Germany, 2014. 
29. Shin, H.-C.; Song, J.-T., High resolution 3-D imaging for characteristics of (111)oriented $\mathrm{Pb}(\mathrm{Zr} 0.35 \mathrm{Ti0} .65) \mathrm{O} 3$ thin film by using time-of-flight secondary ion mass spectrometry and piezoresponse force microscopy. Electron. Mater. Lett. 2011, 7 (3), 265-270.

30. Swart, H. C.; Nagpure, I. M.; Ntwaeaborwa, O. M.; Fisher, G. L.; Terblans, J. J., Identification of Eu oxidation states in a doped Sr5(PO4)3F phosphor by TOF-SIMS imaging. Opt. Express 2012, 20 (15), 17119-17125.

31. Shimizu, N.; Hart, S. R., Isotope fractionation in secondary ion mass spectrometry. Journal of Applied Physics 1982, 53 (3), 1303-1311.

32. Sahu, D. K.; Agrawal, S.; Saji, J., Study the Hardness Properties of TiAlN Coatings Prepared by Magnetron Co-sputtering Deposited Nanoscale Multi-layered Structure. AIP Conference Proceedings 2011, 1372 (1), 318-322.

33. Drozdov, M. N.; Vostokov, N. V.; Danil'tsev, V. M.; Demidov, E. V.; Drozdov, Y. N.; Khrykin, O. I.; Shashkin, V. I., Quantitative analysis of the elemental composition and electron concentration in $\mathrm{AlGaN} / \mathrm{GaN}$ heterostructures with a two-dimensional electron channel by means of SIMS and C-V profiling. Bull. Russ. Acad. Sci. Phys. 2012, 76 (2), 221-224.

34. Chou, H.; Ismach, A.; Ghosh, R.; Ruoff, R. S.; Dolocan, A., Revealing the planar chemistry of two-dimensional heterostructures at the atomic level. Nature Communications 2015, 6 .

35. Schnieders, A.; Budri, T. In Full wafer defect analysis with time-of-flight secondary Ion Mass Spectrometry, Advanced Semiconductor Manufacturing Conference (ASMC), 2010 IEEE/SEMI, 11-13 July 2010; 2010; pp 158-161.

36. Ziemniak, S. E.; Hanson, M., Corrosion behavior of NiCrFe Alloy 600 in high temperature, hydrogenated water. Corrosion Science 2006, 48 (2), 498-521.

37. Sang Ho, L.; Dong Ju, O.; Ah Young, H.; Dong Suk, H.; Shin, K.; Jae Kyeong, J.; Jong Wan, P., Improvement in Device Performance of a-InGaZnO Transistors by Introduction of CaDoped Cu Source/Drain Electrode. Electron Device Letters, IEEE 2015, 36 (8), 802-804.

38. Dhar, R. S.; Ban, D., Two-dimensional profiling of carriers in terahertz quantum cascade lasers using calibrated scanning spreading resistance microscopy and scanning capacitance microscopy. Journal of Microscopy 2013, 251 (1), 35-44.

39. Perea, D. E.; Allen, J. E.; May, S. J.; Wessels, B. W.; Seidman, D. N.; Lauhon, L. J., Three-Dimensional Nanoscale Composition Mapping of Semiconductor Nanowires. Nano Letters 2006, 6 (2), 181-185.

40. Stepien, M.; Saarinen, J. J.; Teisala, H.; Tuominen, M.; Aromaa, M.; Haapanen, J.; Kuusipalo, J.; Mäkelä, J. M.; Toivakka, M., ToF-SIMS Analysis of UV-Switchable TiO2Nanoparticle-Coated Paper Surface. Langmuir 2013, 29 (11), 3780-3790.

41. Carraro, G.; Gasparotto, A.; Maccato, C.; Bontempi, E.; Lebedev, O. I.; Turner, S.; Sada, C.; Depero, L. E.; Van Tendeloo, G.; Barreca, D., Fluorine doped Fe2O3 nanostructures by a one-pot plasma-assisted strategy. RSC Advances 2013, 3 (45), 23762-23768.

42. Höschen, C.; Höschen, T.; Mueller, C. W.; Lugmeier, J.; Elgeti, S.; Rennert, T.; Kögel-

Knabner, I., Novel Sample Preparation Technique To Improve Spectromicroscopic Analyses of Micrometer-Sized Particles. Environmental Science \& Technology 2015, 49 (16), 9874-9880. 43. Gázquez, M. C.; Hernández, T.; Muktepavela, F.; Platacis, E.; Shishko, A., Magnetic field effect on the corrosion processes at the Eurofer-Pb-17Li flow interface. Journal of Nuclear Materials 2015, 465, 633-639.

44. Schreiber, D. K.; Olszta, M. J.; Saxey, D. W.; Kruska, K.; Moore, K. L.; Lozano-Perez, S.; Bruemmer, S. M., Examinations of Oxidation and Sulfidation of Grain Boundaries in Alloy 

Microanalysis 2013, 19 (03), 676-687.

45. Christien, F.; Downing, C.; Moore, K. L.; Grovenor, C. R. M., Quantitative grain boundary analysis of bulk samples by SIMS. Surface and Interface Analysis 2013, 45 (1), 305 308.

46. Gin, S.; Guittonneau, C.; Godon, N.; Neff, D.; Rebiscoul, D.; Cabié, M.; Mostefaoui, S., Nuclear Glass Durability: New Insight into Alteration Layer Properties. The Journal of Physical Chemistry C 2011, 115 (38), 18696-18706.

47. Seebauer, E. G.; Noh, K. W., Trends in semiconductor defect engineering at the nanoscale. Materials Science and Engineering: R: Reports 2010, 70 (3-6), 151-168.

48. Seebauer, E. G.; Dev, K.; Jung, M. Y. L.; Vaidyanathan, R.; Kwok, C. T. M.; Ager, J. W.; Haller, E. E.; Braatz, R. D., Control of Defect Concentrations within a Semiconductor through Adsorption. Physical Review Letters 2006, 97 (5), 055503.

49. Hollister, A. G.; Gorai, P.; Seebauer, E. G., Surface-based manipulation of point defects in rutile TiO2. Applied Physics Letters 2013, 102 (23), 231601.

50. Gorai, P.; Hollister, A. G.; Pangan-Okimoto, K.; Seebauer, E. G., Kinetics of oxygen interstitial injection and lattice exchange in rutile TiO2. Applied Physics Letters 2014, 104 (19), 191602.

51. Gorai, P.; Kondratenko, Y. V.; Seebauer, E. G., Mechanism and kinetics of near-surface dopant pile-up during post-implant annealing. Journal of Applied Physics 2012, 111 (9), 094510. 52. Gorai, P.; Seebauer, E. G., Kinetic model for electric-field induced point defect redistribution near semiconductor surfaces. Applied Physics Letters 2014, 105 (2), 021604. 53. Gorai, P.; Hollister, A. G.; Seebauer, E. G., Electrostatic drift effects on near-surface defect distribution in TiO2. Applied Physics Letters 2013, 103 (14), 141601.

54. Close, T.; Tulsyan, G.; Diaz, C. A.; Weinstein, S. J.; Richter, C., Reversible oxygen scavenging at room temperature using electrochemically reduced titanium oxide nanotubes. Nat Nano 2015, 10 (5), 418-422.

55. Seebauer, E. G.; Jung, M. Y. L.; Kwok, C. T. M.; Vaidyanathan, R.; Kondratenko, Y. V., Measurement of photostimulated self-diffusion in silicon. Journal of Applied Physics 2011, 109 (10), 103708.

56. Vaidyanathan, R.; Felch, S.; Graoui, H.; Foad, M. A.; Kondratenko, Y.; Seebauer, E. G., Nonthermal illumination effects on ultra-shallow junction formation. Applied Physics Letters 2011, 98 (19), 194104.

57. Stathopoulos, S.; Tsetseris, L.; Pradhan, N.; Colombeau, B.; Tsoukalas, D., Millisecond non-melt laser annealing of phosphorus implanted germanium: Influence of nitrogen co-doping. Journal of Applied Physics 2015, 118 (13), 135710.

58. Kondratenko, Y.; Seebauer, E. G., Interface-Mediated Photostimulation Effects on Diffusion and Activation of Boron Implanted into Silicon. ECS Journal of Solid State Science and Technology 2013, 2 (5), P235-P242.

59. Gorai, P.; Hollister, A. G.; Seebauer, E. G., Measurement of Defect-Mediated Oxygen Self-Diffusion in Metal Oxides. ECS Journal of Solid State Science and Technology 2012, 1 (2), Q21-Q24.

60. Pangan-Okimoto, K. M.; Gorai, P.; Hollister, A. G.; Seebauer, E. G., Model for Oxygen Interstitial Injection from the Rutile TiO2(110) Surface into the Bulk. The Journal of Physical Chemistry C 2015, 119 (18), 9955-9965. 